\title{
A RETROSPECTIVE FIVE YEARS STUDY OF PPTCT PROGRAMME IN SMGS HOSPITAL, JAMMU
}

\author{
Swarn Gupta1, Dinesh Kumar ${ }^{2}$
}

${ }^{1}$ Lecturer, Department of Obstetrics and Gynaecology, SMGS Hospital, Government Medical College, Jammu.

${ }^{2}$ Senior Resident, Department of Obstetrics and Gynaecology, SMGS Hospital, Government Medical College, Jammu.

\begin{tabular}{l} 
ABSTRACT \\
\hline BACKGROUND \\
Human Immunodeficiency Virus (HIV) infection is increasing at an alarming rate globally. Apart from heterosexual route, mother- \\
to-child transmission is the next most important route of HIV transmission accounting for over 90\% of infections in children. HIV \\
infection in women occur primarily during their reproductive years, hence pregnancy provides a unique opportunity for \\
implementing prevention strategies against HIV infection.
\end{tabular}

\section{OBJECTIVE}

The present retrospective study is undertaken to evaluate the effectiveness of implementation of PPTCT programme in SMGS Hospital, Jammu.

\section{MATERIAL AND METHODS}

All pregnant women attending antenatal OPD were counselled and tested for HIV. All positive patients were again counselled and ART started. Spouses of all positive women were counselled and tested. Universal work precautions, Modification of labour and delivery practices were followed. All the babies born to positive women received nevirapine prophylaxis for 6 wks and babies were tested at 18 months. Mothers were counselled regarding breast feeding.

\section{RESULTS}

A total of 22,047 ante-natal women were counselled and all of them gave consent for HIV testing. Seropositivity in these women was $0.09 \%$. The no. of positive deliveries (54) exceeded the no. of positive antenatal cases (20). Most of these patients were primis or second gravidas, majority of them were young, belonging to age group of 20-30 yrs and most of them were not well educated; $100 \%$ of spouses were found to be seropositive. Most of these women $(59.26 \%)$ were delivered through vaginal route. LSCS was done for obstetric indication in $40.74 \%$ of cases. There were $100 \%$ live births. ALL the mothers opted for replacement feeding (100\%). Seropositivity of babies born to these mothers could not be calculated due to loss of patients to follow-up.

\section{CONCLUSION}

The PPTCT programme is effective and has reduced the rate of transmission from mother to child. Labour room screening and early infant diagnosis should be introduced in our hospital.

\section{KEYWORDS \\ PPTCT, HIV, ART, Seropositivity.}

HOW TO CITE THIS ARTICLE: Swarn Gupta, Dinesh Kumar. "A Retrospective Five Years Study of PPTCT Programme in SMGS Hospital, Jammu." Journal of Evolution of Medical and Dental Sciences 2015; Vol. 4, Issue 100, December 14; Page: 16554-16557, DOI: $10.14260 /$ jemds/2015/2464

\section{INTRODUCTION \\ There were approximately 36.9 million people living with HIV at the end of 2014 with two million people becoming newly infected with HIV in 2014 globally. The mother to child transmission of HIV refers to the transmission of HIV from an HIV positive woman to her child during pregnancy, labour, delivery and breast feeding. MTCT is by far the most common way that children became infected with HIV (90\%). ${ }^{1}$ Without treatment, the likelihood of HIV passing from women to child is $15 \%$ to $45 \%$; however, antiretroviral treatment and other effective interventions for the prevention of MTCT can reduce the risk to below $5 \%{ }^{2}$}

Financial or Other, Competing Interest: None.

Submission 20-11-2015, Peer Review 21-11-2015,

Acceptance 05-12-2015, Published 14-12-2015.

Corresponding Author:

Dr. Dinesh Kumar,

70/7, Model Town, Gangyal,

Jammu-180010,

$J \& K$.

E-mail: drdinesh1982@yahoo.com

DOI:10.14260/jemds/2015/2464
Effective PMTCT programmes require women and their infants to receive a cascade of interventions including uptake of antenatal services, HIV testing during pregnancy, use of antiretroviral treatment by pregnant women living with HIV, safe child birth practices and appropriate infant feeding, uptake of infant HIV testing and other post-natal healthcare services. $^{3}$ WHO identified 22 priority countries with the top ten including India accounting for $75 \%$ of the global PMTCT services need. It was estimated that the effective scaling up of PMTCT interventions in these countries would prevent over 250,000 new infections annually. ${ }_{4}$ Cuba became the first country to be validated by the WHO to have eliminated mother to child transmission of HIV on $30^{\text {th }}$ of June, 2015. ${ }^{1}$

In developing countries like India, it was believed that husbands were mostly responsible for transmission of HIV in mothers through the sexual route and therefore they are considered to be equally responsible for the transmission of HIV to their children. In India therefore PMTCT is termed as PPTCT (Prevention of Parent-To-Child Transmission), so that mothers alone should not be blamed for HIV in their children. India's PPTCT programme started in 2002. Based on 2013 WHO guidelines, the programme aims to initiate antiretroviral treatment for all pregnant and breastfeeding women living 
with HIV regardless of the trimester of pregnancy, CD4 count and WHO stage. 5

The aim of this retrospective study is to evaluate the effectiveness of PPTCT programme implementation at SMGS Hospital, GMC, Jammu, for a period between January 2010 to December 2014.

\section{MATERIAL AND METHODS}

This is a retrospective study conducted at the Department of Obstetrics and Gynecology in SMGS Hospital, GMC, Jammu, from January 2010 to December 2014 for a period of five years. The material was obtained from the ICTC Centre in the SMGS Hospital and ART Centre in GMC, Jammu. The ICTC Centre in the antenatal OPD in SMGS Hospital Jammu offers HIV counselling (group/individual) and testing to all pregnant women attending antenatal care with opt out option. In pretest counselling, women are explained the significance of the test and the consequences of both a positive and negative result. Gaps in their knowledge about HIV/AIDS are filled up and degree of risk for an individual woman is assessed. Blood samples are collected after taking consent for HIV testing.

Post-test counselling is done and it involves proper counselling about HIV, ART, regular exercise, healthy lifestyle and diet, safe sex practices and most importantly the importance of adherence and institutional delivery. A woman is confirmed positive after three rapid tests. The spouses of the positive women are tested for HIV after pre-test counselling and test is followed by post-test counseling. CD4 cell count is done for the positive women. From January 2010 to December 2013, ART was started in HIV positive women with CD4 $\leq 350$ cells $/ \mathrm{mm}^{6}{ }^{6}$ or WHO clinical stage 3 or 4 . From January 2014 to December 2014 lifelong ART was initiated for the women regardless of the trimester of pregnancy, CD4 count and WHO stage consisting of a triple-drug ART regimen Tenofovir (TDF) 300mg + Lamivudine (3TC) $300 \mathrm{mg}+$ Efavirenz (EFV) 600mg. Known HIV positive cases and already at ART, ART was continued.

Our hospital lacks provision of HIV screening in labour room. All the positive deliveries were either booked with ART centre of our hospital or with other centres of the province. In our hospital, during labour, HIV positive women received single dose nevirapine $200 \mathrm{mg}$ from January 2010 to
December 2013 and from January 2014 to December 2014, triple-drug ART regimen during antenatal period was continued. Universal work precautions were taken, vaginal examinations were minimized and all aseptic techniques were used, artificial rupture and membranes was avoided, routine episiotomy was not done and instrumental delivery was minimized. Cesarean section was performed only for obstetrical indication.

Routine suctioning of newborn with a nasogastric tube was avoided except in meconium staining of the liquor, early clamping of umbilical cord was done after delivery. All babies received nevirapine immediately after birth and were counselled regarding infant feeding. Benefits and risks of both Exclusive Breast Feeding (EBF) and Exclusive Replacement Feeding (ERF) were explained. Exclusive replacement feeding was allowed, but only in condition that they fulfilled the A (Affordable), F (Feasible), A (Acceptable), S (Sustainable), S (Safe) criteria. Risk of mixed feeding was also explained. From January 2010 to December 2013, HIV exposed infants received single dose of nevirapine syrup only at the time of birth and from January 2014 to December 2014 ARV prophylaxis to HIV exposed infant was started at birth in the form of daily nevirapine for six weeks for both EBF and ERF babies.

For infants weighing less than $2 \mathrm{~kg}$ nevirapine dose was $0.2 \mathrm{ml} / \mathrm{kg}, 2-2.5 \mathrm{~kg} 1 \mathrm{ml}$, more than $2.5 \mathrm{~kg} 1.5 \mathrm{ml}$ of the suspension once a day $(10 \mathrm{mg}$ of nevirapine in $1 \mathrm{ml}$ of suspension). Daily nevirapine was given for six weeks for both EBF and ERF babies. Co-trimoxazole prophylaxis was started at 6 wks and continued up to 18 months when HIV was ruled out. It was given in the dose of $2.5 \mathrm{ml}, 5 \mathrm{ml}, 7.5 \mathrm{ml}$ and $10 \mathrm{ml}$ for baby weight $<5 \mathrm{~kg}, 5-10 \mathrm{~kg}, 10-15 \mathrm{~kg}$ and $15-22 \mathrm{~kg}$ respectively. ( $5 \mathrm{ml}$ of syrup containing 40mg TMP/200 SMX). An assessment of the child's development was done at regular intervals. Growth monitoring and immunization was done as per schedule.

The ICTC and ART centres in our hospital lacks the provision of Early Infant Diagnosis by DNA PCR testing of dried blood spots/whole blood samples of babies at 6 wks. Only those babies were tested which show clinical symptomatology of HIV infection like failure to thrive, delayed milestones, etc. Final confirmation of HIV status of baby was done at 18 months by doing all three rapid tests for antibody detection.

\section{RESULTS}

The data collected from PPTCT programme of our institute. The data is tabulated and results are as follows:

\begin{tabular}{|c|c|c|c|c|}
\hline Year & $\begin{array}{c}\text { No. of Antenatal } \\
\text { Cases Counselled }\end{array}$ & $\begin{array}{c}\text { No. of Antenatal } \\
\text { Cases Tested }\end{array}$ & $\begin{array}{c}\text { No. of Cases } \\
\text { Found Positive }\end{array}$ & $\begin{array}{c}\text { No. of Positive } \\
\text { Deliveries }\end{array}$ \\
\hline 2010 & 2822 & 2822 & - & 8 \\
\hline 2011 & 3464 & 3464 & 4 & 9 \\
\hline 2012 & 5086 & 5086 & 3 & 13 \\
\hline 2013 & 5050 & 5050 & 3 & 12 \\
\hline 2014 & 5625 & 5625 & 6 & 12 \\
\hline Total & $\mathbf{2 2 0 4 7}$ & $\mathbf{2 2 0 4 7}(100 \%)$ & $\mathbf{2 0 ~ ( 0 . 0 9 \% )}$ & $\mathbf{5 4}$ \\
\hline \multicolumn{6}{|l}{ Table 1: Year wise Antenatal women tested, seropositive and positive deliveries } \\
\hline
\end{tabular}

\begin{tabular}{|c|c|c|c|}
\hline Year & $\begin{array}{c}\text { No. of } \\
\text { Positive } \\
\text { Deliveries }\end{array}$ & $\begin{array}{c}\text { No. of Vaginal } \\
\text { Deliveries }\end{array}$ & $\begin{array}{c}\text { No. of } \\
\text { LSCS }\end{array}$ \\
\hline 2010 & 8 & 4 & 4 \\
\hline 2011 & 9 & 6 & 3 \\
\hline 2012 & 13 & 10 & 3 \\
\hline 2013 & 12 & 6 & 6 \\
\hline 2014 & 12 & 6 & 6 \\
\hline Total & 54 & 32(59.26\%) & 22(40.74\%) \\
\hline \multicolumn{4}{|c|}{ Table 2: Year wise Mode of Delivery of } \\
seropositive delivered women \\
\hline
\end{tabular}

\begin{tabular}{|c|c|c|c|}
\hline Year & $\begin{array}{c}\text { No. of Live } \\
\text { Births }\end{array}$ & $\begin{array}{c}\text { Still } \\
\text { Births }\end{array}$ & IUD \\
\hline 2010 & 8 & - & - \\
\hline 2011 & 9 & - & - \\
\hline 2012 & 13 & - & - \\
\hline 2013 & 12 & - & - \\
\hline 2014 & 12 & - & - \\
\hline Total & $\mathbf{5 4 ( 1 0 0 \% )}$ & - & - \\
\hline \multicolumn{2}{|l}{ Table 3: Delivery outcome of seropositive deliveries } \\
\hline
\end{tabular}




\begin{tabular}{|c|c|c|c|c|c|}
\hline Year & $\begin{array}{c}\text { No. of Positive } \\
\text { Deliveries }\end{array}$ & Primis & Gravida 2 & Gravida 3 & $\begin{array}{c}\text { Gravida more } \\
\text { than four }\end{array}$ \\
\hline 2010 & 8 & 8 & - & - & - \\
\hline 2011 & 9 & 7 & 2 & - & - \\
\hline 2012 & 13 & 8 & 2 & 3 & - \\
\hline 2013 & 12 & - & 3 & 4 & 5 \\
\hline 2014 & 12 & - & 4 & 4 & 4 \\
\hline Total & $\mathbf{5 4}$ & $\mathbf{2 3}$ & $\mathbf{1 1}$ & $\mathbf{1 1}$ & $\mathbf{9}$ \\
\hline
\end{tabular}

\begin{tabular}{|c|c|c|c|c|c|}
\hline Year & No. of Positive Deliveries & $\mathbf{1 5 - 1 9}$ yrs & $\mathbf{2 0 - 2 4}$ yrs & $\mathbf{2 5 - 3 0}$ yrs & 31-35 yrs \\
\hline 2010 & 8 & - & 3 & 3 & 2 \\
\hline 2011 & 9 & 3 & 5 & - & 1 \\
\hline 2012 & 13 & 2 & 1 & 6 & 4 \\
\hline 2013 & 12 & - & 6 & 5 & 1 \\
\hline 2014 & 12 & - & 4 & 7 & 1 \\
\hline Total & 54 & $\mathbf{5}$ & $\mathbf{1 9}$ & $\mathbf{2 1}$ & $\mathbf{9}$ \\
\hline \multicolumn{4}{|l}{} \\
\hline
\end{tabular}

\begin{tabular}{|c|c|c|c|c|c|}
\hline Year & No. of Positive Deliveries & Illiterate & Up to 10 & Up to 12 & >12 $^{\text {th }}$ \\
\hline 2010 & 8 & 2 & 4 & 2 & - \\
\hline 2011 & 9 & 3 & 3 & 3 & - \\
\hline 2012 & 13 & 3 & 9 & 1 & - \\
\hline 2013 & 12 & 4 & 8 & - & - \\
\hline 2014 & 12 & 2 & 8 & 2 & - \\
\hline Total & 54 & 14(25.9\%) & 32(59.3\%) & 8(14.8\%) & - \\
\hline \multicolumn{6}{|l}{}
\end{tabular}

\section{DISCUSSION}

In our study between January 2010 - December 2014, a total of 22,047 antenatal patients were counselled and all of them consented for testing with acceptance rate of $100 \%$. HIV seroprevalence rate in antenatal cases in our study was found out to be $0.09 \%$, which is lower than the national average seroprevalence rate in antenatal cases of $0.35 \%$. Vellanki VS et al. ${ }^{6}$ found seroprevalence of $1.12 \%$ and Kulkarni SK et al. ${ }^{7}$ found $0.76 \%$.

Since our centre is a tertiary referral centre in the province, the number of positive deliveries exceeded the no. of positive antenatal cases. Majority of these patients were young between 20 to $30 \mathrm{yrs}$. Majority of these patients were primis and second gravidas. This is comparable to study by Saritha $\mathrm{K}$ et al. ${ }^{8}$ Majority of serpositive women had low educational status with $25.9 \%$ were illiterate and $59.3 \%$ were studied up to $X^{\text {th }}$ standard. This may be due to lack of awareness about HIV transmission in these groups. This is in accordance with study by Singh LS et al. ${ }^{9}$ who found maximum no. of HIV seropositivity in illiterates $(23.6 \%)$ and in those who studied up to class X (52.9\%).

All the spouses of 20 antenatal seropositive women were offered counselling and all of them gave consent for testing with an acceptance rate of $100 \%$. All the spouses found HIV positive after testing, so seropositivity of spouses in our study was $100 \%$, whereas Vellanki VS et al. ${ }^{6}$ reported seroprevalence of spouses as $80.55 \%$. No seropositive woman in our study opted for MTP or permanent sterilization. Delivery by vaginal route took place in most of the cases (59.26\%) and LSCS was performed only for obstetric indications in $40.74 \%$ of cases. Our results are comparable with study by Saini VK et al. ${ }^{10}$ who found $62.4 \%$ seropositive women delivered vaginally and $37.6 \%$ women delivered by LSCS.

HIV virus is transmitted through breast milk. Transmission rates for breastfeeding mothers may be as high as $30-40 \%{ }^{11}$ Breast feeding is not recommended for HIV infected women in developed countries, although WHO recommends breastfeeding with early weaning by 6 months for women living in developing countries where infectious diseases and malnutrition are the primary causes of infant death. ${ }^{12}$ In our study after explaining the pros and cons of breastfeeding and replacement feeding, the number of women opting for exclusive replacement feeding were $100 \%$.

Seroprevalence of babies could not be calculated as there was paucity of data at 18 months due to babies migrating and getting tested at another centres. Out of 54 positive deliveries, only 4 babies could be followed up who received nevirapine for $6 \mathrm{wks}$ and found seronegative after testing at 18 months.

\section{CONCLUSION}

There is need to further strengthen the PPTCT programme in our hospital. Labour room screening should be started to prevent any unbooked case remaining undiagnosed. Proper counselling of the parents should be done, so that they remain adhere to our center for the follow-up of their infants. Early infant diagnosis by DNA PCR testing at 6 wks should be introduced in our hospital as per recommendations. With these improvements we will definitely achieve the goal of elimination of parent to child transmission of HIV.

\section{REFERENCES}

1. AIDS info (2014) HIV prevention: Preventing mother to child transmission of HIV (cited 2015 Aug 2015). Available from:

https://aidsinfo.nih.gov/education-materials/factsheets/20/50/preventing-mother-to-childtransmission-of-HIV.

2. WHO (2014) HIV/AIDS: Prevention of mother to child transmission of HIV (cited 2015). Available from: http://www.who.int/hiv/topics/mtct/en.

3. Padian NS, McCoy SI, Karim SA, et al. HIV prevention transformed: the new prevention research agenda. Lancet. 2011 Jul 16;378(9787):269-278. 
4. WHO (2013) 'Global report: UNAIDS report on the global AIDS epidemic 2013 (cited Nov. 2013). Available from:

http://www.unaids.org/sites/default/files/media_asset /UNAIDS_Global_Report_2013_en_1.pdf

5. NACO (2014) 'Annual Report 2013-2014 (cited 2014, June 30). Available from:http://www.naco.gov.in/upload/2014\%20mslns/ NACO_English\%202013-14.pdf

6. Vellanki VS, Gunti SPS, Prasad VG, et al. Seroprevalance of HIV in women attending antenatal clinic at KIMS hospital, Narketpall Int J Reprod Contracept Obstet Gynecol. 2012 Dec;1(1):17-21.

7. Kulkarni SK, Doibale MK. Trend of seroprevalence of HIV among antenatal clinic attendees at a tertiary care hospital international journal of basic and applied medical sciences 2013) January-April ;3(1):257-262.
8. Saritha K, Himabindu P, Shobitha GL, et al. A retrospective 5-year study of PPTCT Programme at Tertiary Care Centre, Journal of Evolution of Medical and Dental Sciences 2015 June; Vol. 4, Issue 46.

9. Singh LS, Devi PR, Phesao E, Singh NN, Singh AY, Kom TT. Prevalence of HIV seropositive delivery in a tertiary care hospital, Manipur. J Med Soc 2015;29:8-11.

10. Saini VK, Sharma SV. Recent trends of HIV transmission from mother to child: Retrospective study of 4 years in a tertiary centre. International Journal of Scientific Research. Volume 4, Issue 9 Sept 2015.

11. Kourtis AP, Jamieson DJ, de Vincenzi I, Taylor A, Thigpen $\mathrm{MC}$, Dao H, et al. Prevention of human immunodeficiency virus -1 transmission to the infant through breastfeeding: new developments. Am J Obstet Gynecol 2007 sep;197(3 suppl);S113-22.

12. World Health Organization: HIV transmission through breast feeding; A review of available evidence: 2007 update. Geneva, WHO Press, 2008. 